\title{
Study on Relay Protection of Small Hydro- power Station in Isolated Power Grid
}

\author{
Cao Mingzhe \\ Dagu south Road No.1310 Hexi District Tianjin China \\ Tianjin Key Laboratory of Information Sensing and \\ Intelligent Control; \\ Tianjin, China \\ 849738243@qq.com \\ Yang Genghuang \\ Dagu south Road No.1310 Hexi District Tianjin China \\ Tianjin Key Laboratory of Information Sensing and \\ Intelligent Control; \\ Tianjin, China \\ ygenghuang@126.com
}

\author{
Su Xin \\ Hongqi Road No. 278, Nankai District, Tianjin, China \\ Chengxi Power Supply Bureau, Tianjin POWER GRID \\ Tianjin, China \\ susin@126.com \\ Wang Qingling \\ Guanshansi Road No. 2, Maoming, China \\ Maoming Power Supply Bureau, Guangdong POWER \\ GRID \\ Maoming China \\ ashe_11@126.com
}

\begin{abstract}
Because the trend in small hydro-power micro grid flows bi-directionally, the traditional strategy which based on phase voltage change and load shedding has become increasingly unreliability. In order to adapt to the new application environment of small hydro-power micro grid, and to improve the protection installations, reliability and accuracy, longitudinal differential protection is used in power feeder with small hydro-power, so as to avoid the disadvantages of the traditional strategy. Constructing a micro grid with hydro-power stations working in isolated power grid by PSCAD/EMTDC software is used to prove that the strategy is effective and practicable .
\end{abstract}

Keywords-Small hydro-power station; Longitudinal differential protection ; isolated power grid ; Micro grid ; PSCAD/EMTDC

\section{INTRODUCTION}

Because of its low cost and flexibleness, the Small hydro-power station that refers to the capacity at $25 \mathrm{MW}$ or below, has become a common distributed power supply[1]. The station runs parallel with the outside distribution power network except for few special cases, it isolates from the distribution network to meet local power demand[2]. However, as the result of the station distributes widely, the trend in small hydro-power micro grid often flows bi-directionally, the traditional protection strategy which is based on only one end electric signal of protected area, fails to provide accurate signals to reclosing. Thus, the traditional strategy of distribution network protection should be replaced in the new application environment with two ends power supply [3-5].

This paper includes a new protection strategy by longitudinal differential protection. Also the effectiveness of this strategy when the micro grid isolates from the distribution network is verified through the model built by the software of PSCAD/EMTDC.

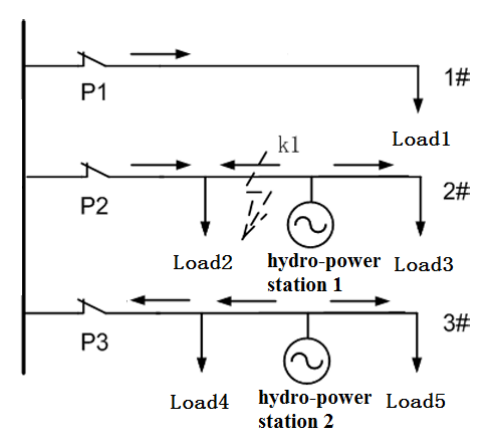

Figure 1. Small hydro-power micro grid in isolated power grid

\section{LONGITUDINAL DIFFERENTIAL PROTECTION}

A. the Principle of longitudinal differential protection

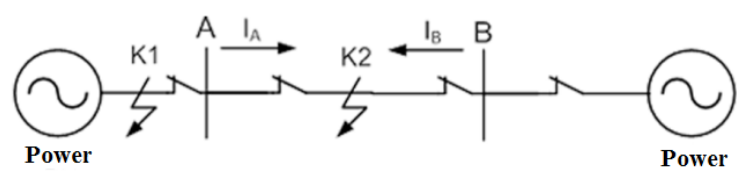

Figure 2. Schematic diagram of longitudinal differential protection

The longitudinal differential protection is a strategy which based on the large current's difference between the protection area and non-protection area. As Fig .2 shows, in the ideal case, when the fault earthing occurs in K1, then $\sum I_{K 1}=I_{A}+I_{B}=0$.But in engineering applications, due to TA error, electrical susceptance and cable factors, then $\left|I_{A}+I_{B}\right| \geq I_{\text {set }}$ ( $I_{\text {set }}$ is the threshold value). In addition, when the fault earthing occurs in protected area in $\mathrm{K} 2$ point, ignoring the effects of electrical susceptance and cable, fault current in $\mathrm{K} 2$ is $\sum I_{k 2}=I_{A}+I_{B}$ [5-7]. 


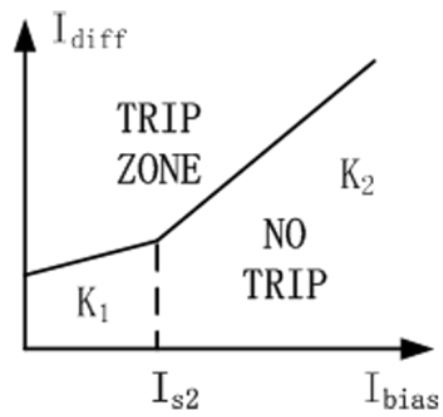

Figure 3. Dual slope differential current relay braking characteristics

As Fig 3 shows, there are four parameters:

IS1: based differential current parameters;

IS2: slope threshold current parameter;

$\mathrm{K} 1$ : the low slope parameter;

$\mathrm{K} 2$ : for high slope parameter.

\section{B. Longitudinal differential protection module}

In Fig .1, 2\# and 3\# feeder, because of the flexible distribution of small hydro-power stations, the trend flows bi-directionally in the micro grid. Because the longitudinal differential protection detects the signal of two ends of the protected area, the majority of selective disorders can be avoided effectively.

Meanwhile, the action time of the breaker in two ends is almost the same as one end, and the time error between the actions is below $1 \mathrm{~ms}$. Therefore, when the breaker acts, the hydro-power stations can be cut from the power system, avoiding transient fault conversion to permanent fault [8$11]$.

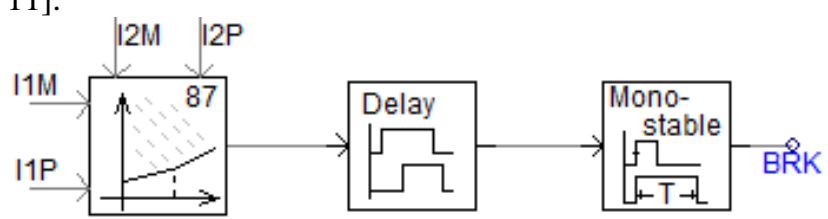

Figure 4. The Longitudinal differential protection module

As Fig .4 shows, in the PSCAD-EMTDC component library, longitudinal differential protection module is consisted by a Dual Slope Current Differential and a delay element as well as a Monostable Multivibrator.

\section{SMALL HYDRO-POWER STATION MODELING}

\section{A. simulation models of synchronous generator and excitation system}

Synchronous generator and its excitation system is the core of small hydro-power system. Synchronous generator and its excitation module is shown in Fig .5(a). Vref is the reference voltage of the generator. VT and IT are the generator's actual voltage and current. Ef and If are the excitation voltage and current respectively. Ef0 is the initial voltage of excitation system[12-13].

The working process of this module is: the excitation system compares the voltage and current of generator with the set threshold firstly, and then gets the deviation is obtained, the control part of the excitation system is adjusted to stabilize the generator terminal voltage lastly[14-15].

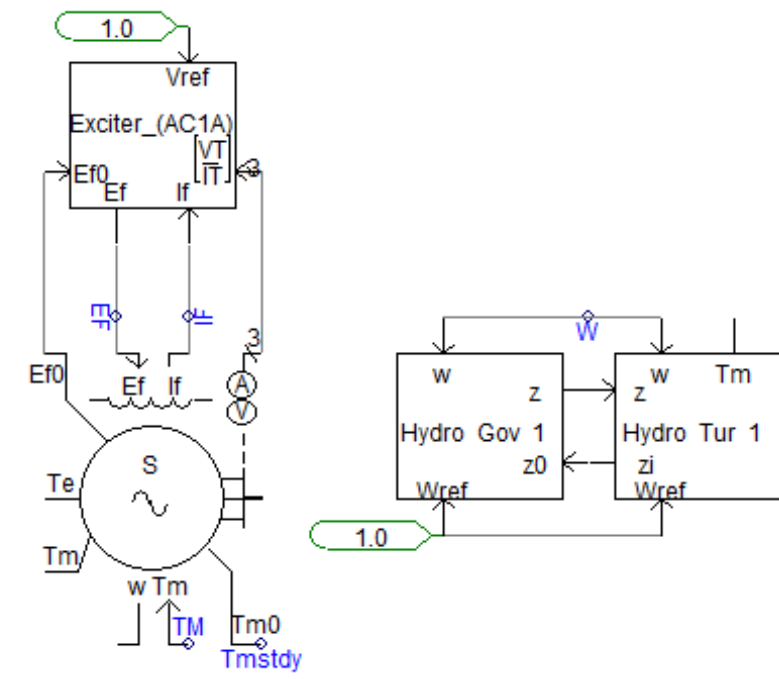

Figure 5 (a). synchronous generator and its excitation module (b) hydraulic turbine speed control module

\section{B. Speed regulating system of turbine module}

As Fig .5 (b) shows, in PSCAD/EMTDC platform, the hydraulic turbine speed control module (Hydro Gov1) and the turbine module (Hydro Tur1) is constructed into a water turbine and its speed control system model. Among them, the turbine speed $\mathrm{w}$ is the control object, Wref is the given speed. hydraulic turbine speed is controlled by opening Z [16]

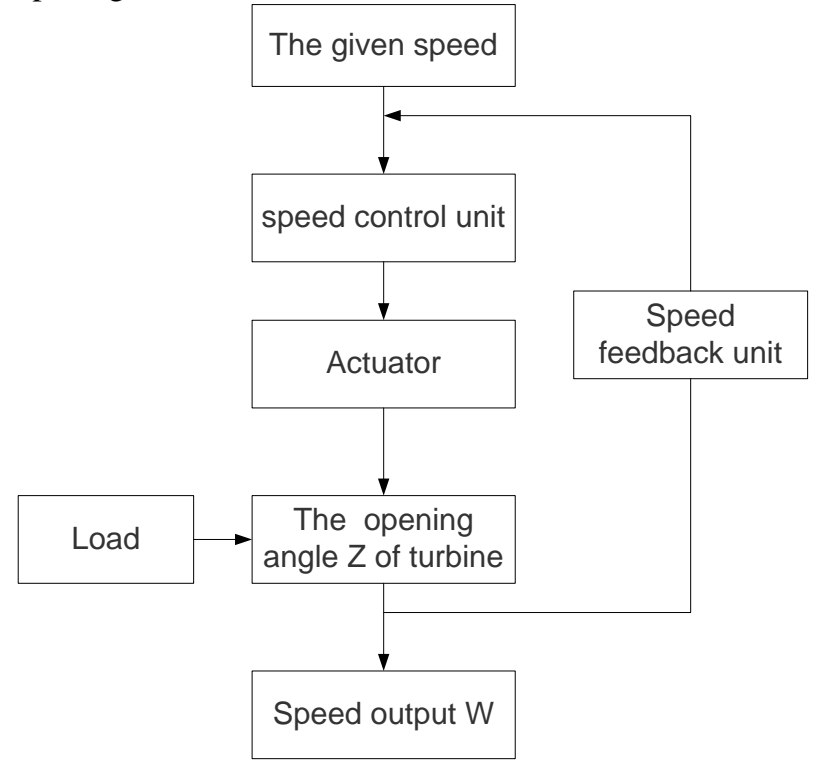

Figure 5(b). The flow of the speed control

IV. SIMULATION OF SINGLE-PHASE FAULT EARTHING OF K1 IN 2\# FEEDERS IN ISOLATED NETWORK OPERATION.

In PSCAD/EMTDC, a small hydro-power system and its corresponding protection modules are constructed, and the protection strategy in isolated network operation is test.

The longitudinal differential protection modules are constructed on both ends of the $\mathrm{K} 1$ point to test the effectiveness of the protection strategy. With longitudinal differential protection module in $2 \#$ feeder, when single- 
phase fault earthing occurs, the whole process of current and voltage waveform is shown in pictures Fig .6-8.

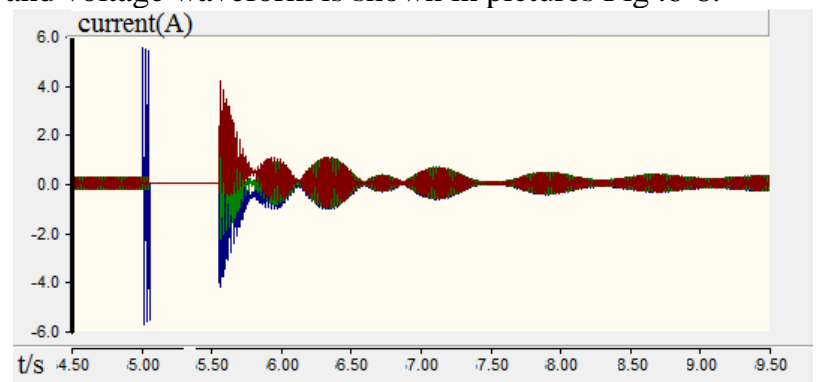

Figure 6(a). hydro-power station 2 feeding current $4.5 \sim 9.5 \mathrm{~s}$

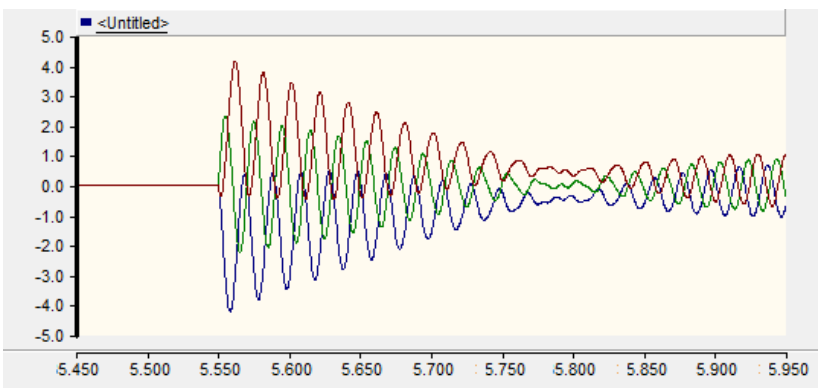

Figure 6(b). hydro-power station 2 feeding current5.450 5.950s

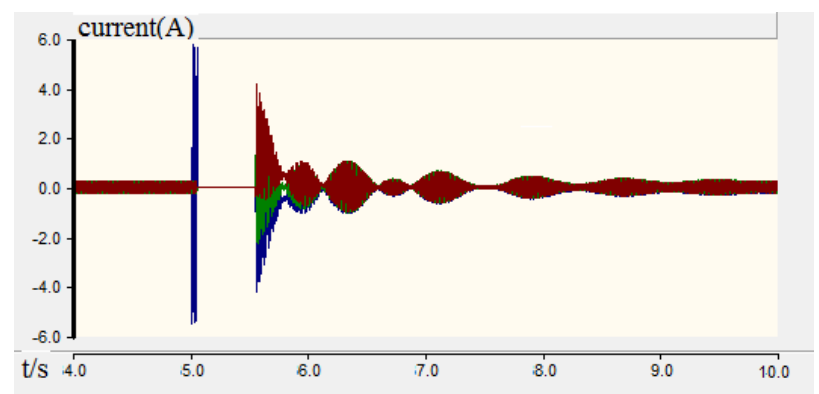

Figure 7(a). hydro-power station 1 feeding current4.0 10.0s

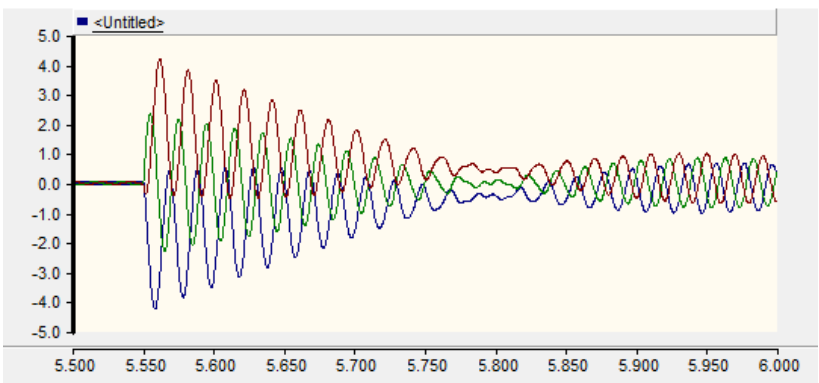

Figure 7(b). hydro-power station 1 feeding current 5.5 6.0s

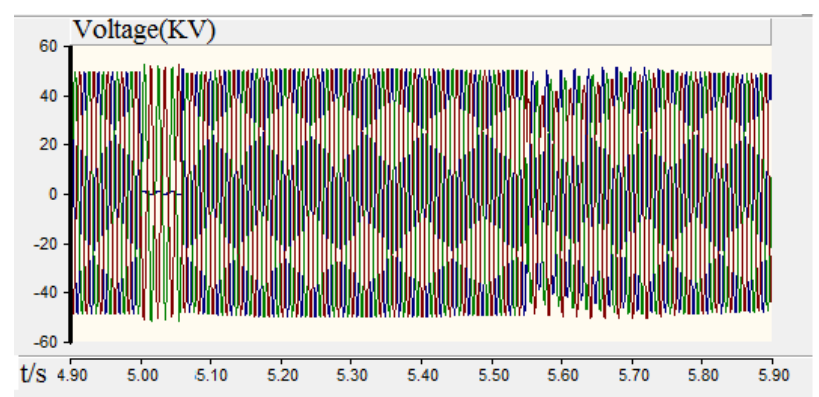

Figure 8(a). Voltage of the micro grid system 4.90 5.90s

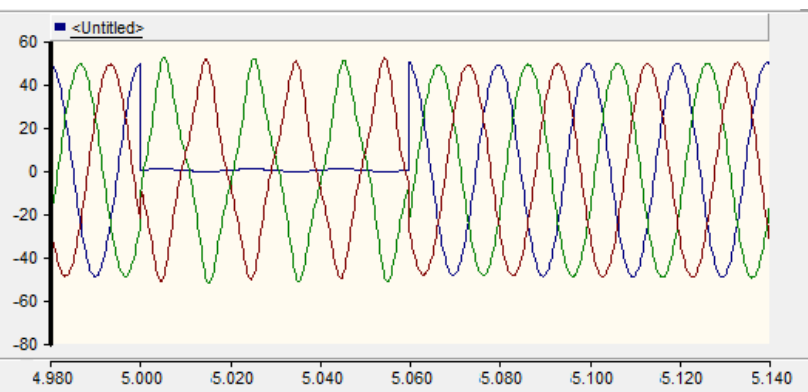

Figure 8(b). Voltage of the micro grid system 4.980 5.140s

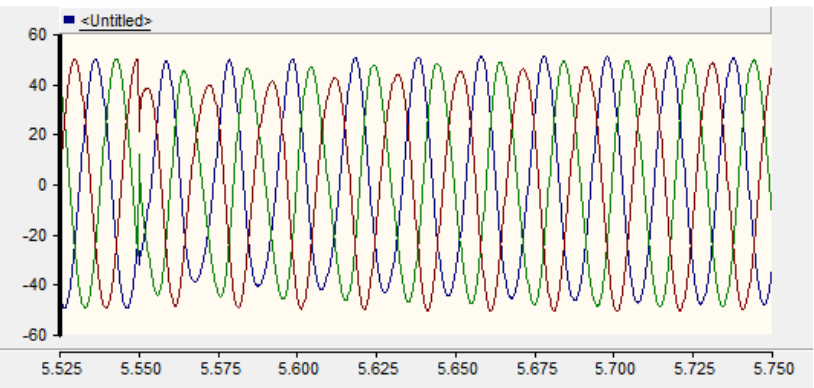

Figure 8(c). Voltage of the micro grid system 5.525 5.750s

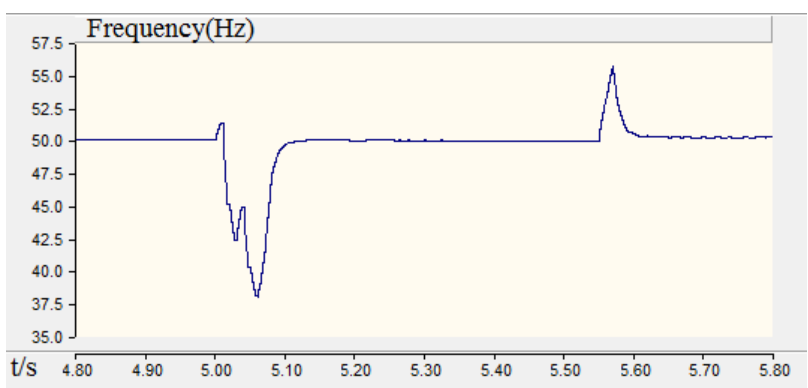

Figure 9. Frequency of the micro grid system 4.80 5.80

From pictures above, when the phase earth fault occurs, the phase fault's current increases rapidly, but the frequency of the system drops to $37.5 \mathrm{~Hz}$. Besides the voltage in no fault phases climbs slightly, conversely the fault phase decreases to almost $0 \mathrm{~V}$.

The protection acts at $0.05 \mathrm{~s}$ after the phase earth fault occurs and lasts $0.5 \mathrm{~s}$. During the $0.5 \mathrm{~s}$ of fault, the current drops to $0 \mathrm{~A}$ until the reclosing acts .In addition to this, there is a sharp increase in frequency from $37.5 \mathrm{~Hz}$ to the normal value $50 \mathrm{~Hz}$. However, the voltage remains stable.

After reclosing acts, the current fluctuates greatly and it becomes stable after about 5s. There is a steadily increase of frequency and after $0.05 \mathrm{~s}$ the value reaches a plateau at $50 \mathrm{~Hz}$. But the change of the voltage is not as dramatically as the current, only after $0.3 \mathrm{~s}$ it reaches to rated value.

The longitudinal differential protection module can detect and act correctly, and reclose the breakers successfully .

\section{CONCLUSION}

This paper analyzes the principle of longitudinal differential protection which is commonly used in the distribution network, and using it in the micro grid with small hydro-power station. Moreover, a simple and 
practical system is built in the PSCAD/EMTDC platform, so as to detect the effectiveness of this new method, providing another reliable scheme for the protection of small hydro-power in micro grid.

At the same time, some factors are ignored, such as the energy storage elements, the topological structure of the system and the time of simulation. Thus, if more scientific characteristics of the micro grid are required, more aspects and factors in application environment should be considered.

\section{ACKNOWLEDGMENT}

This work is supported by Guangdong POWER GRID Maoming Power Supply Bureau (K-GD2014-1023)

\section{REFERENCE}

[1] SINGH G K. Multi-phase induction machine drive reserch-a survey[J]. Electric Power Systems Research， 2003， 62 : 139-147.

[2] He Jiali, Song Congju. Principle of Power System Relay Protection[M]. Beijing : China Power Press, 1994 : 130-141.

[3] A Shafiu, O Anaya-Lara, G Bathurst, et al. Aggregated wind turbine models for power system dynamic studies[J]. Wind engineering, 2006, 30(3): 171-186

[4] EA Zhi jun. Based on the PSCAD/EMTDC power system electromechanical and electromagnetic transient hybrid simulation [D].Tianjin: Tianjin University, 2005

[5] Cai Wei from.2000. hydraulic turbine governor [M]. Wuhan: Wuhan University of hydraulic and electric power press: 37

[6] long Ruihua. Small hydro electricity system on the improvement of reclosing success rate of [D]. Hunan University, 2010

[7] Jin Xin kun,He Zi jun, Liu Zong qi. Multi-Agent-based Cloud Architecture of Smart Grid[A]. 2011 International Conference on
Smart Grid and Clean Energy Technologies[C]. ICSGCE,2011: 38 41

[8] Han Xiao, Jin Xinkun, Xu Shiyu. The Integration Technology of Smart Protection and Control Device in Rural Distribution Network[A]. 2010 China International Conference on Electricity Distribution[C]. IEEE, 2010: 1-3

[9] Xiao Hongfei, Liu Shirong, Zheng Lingyu, et al. Study on technology of micro grid $[\mathrm{J}]$. power system protection and control of.2009,37 (8):114-119

[10] Ding Fei. The modeling and Simulation of transient [D] Containing a variety of distributed power supply and Tianjin University low-voltage microgrid energy storage: 2010

[11] Pei Wei, Li Shusen, Li Huiyu, et al. Q automation of electric power system [J]. and the key technology of test platform of microgrid operation control,2010,34:: 94-100.

[12] Bartosz Wojszczyk, Omar Al-Juburi, Joy Wang. Impact of high penetration of distributed generation on system design and operations $[J]$. Power System Technology, 2009, 33(15) : 37-46(in Chinese)

[13] Zeng Zheng, Yang Huan, Zhao Rongxiang. A catastrophe decision theory based power quality comprehensive evaluation method for distributed generation system $[\mathrm{J}]$. Automation of Electric Power Systems, 2011，35(21) : 52-57(in Chinese).

[14] Hu J B, Zhang W, Wang H S, et al. Proportional integral plus multi-frequency resonant current controller for grid-connected voltage source converter under imbalanced and distorted supply voltage conditions[J]. Journal of Zhejiang University-Science, 2009, 10(10) : 1532-1540.

[15] Vegunta S C, Milaniovic J V. Estimation of cost ofdowntime of industrial processes due to voltagesags[J]. IEEE Trans. on Power Delivery, 2011, 26(2) : 576-587

[16] Jayawarna, N. Jenkins, N. Barnes, M. Lorentzou, M. Papthanassiou, S. Hatziagyriou,N. Safety analysis of a microgrid[C]. 2005 International Conference on Future Power Systems, 2005,11(18): $1-7$. 